\title{
A clínica psicanalítica no século XXI: de que humano se trata?
}

\author{
The psychoanalytic clinic in the $\mathbf{2 1}$ st century: what human is it about?
}

\author{
Marlize Rêgo', Maria Eugenia Nuñez ${ }^{2}$ \\ 'Centro de Estudos e Terapia do Abuso de Drogas - CETAD, Universidade Federal da Bahia. Salvador, Bahia, Brasil. marlizerego@oi.com.br \\ ${ }^{2}$ Centro de Estudos e Terapia do Abuso de Drogas - CETAD, Universidade Federal da Bahia. Salvador, Bahia, Brasil. nunezeugenia@hotmail.com
}

RESUMO I A partir de relatos do cotidiano, este trabalho reflete sobre fenômenos que se apresentam na contemporaneidade com características de explícito e sobre o alcance da clínica psicanalítica, tanto no que diz respeito às queixas e demandas que se apresentam de formas diversificadas e com roupagens inusitadas, quanto às estratégias de abordagem que devem ser estabelecidas ao longo do processo analítico. As inquietações diante destes fenômenos provocam questionamentos por parte de psicanalistas, filósofos, antropólogos, psiquiatras, entre outros, em relação às mudanças ocorridas no mundo contemporâneo e a aposta na construção de uma nova clínica que responda aos novos modos sintomáticos a partir de uma nova ética. Considerando o diálogo entre a psicanálise e vários outros campos de saber, este ensaio teórico estabelece uma tessitura entre a contemporaneidade, a clínica psicanalítica e a noção de humano, destacando os dois principais sentidos do conceito de vulnerabilidade, a saber, a vulnerabilidade social e a vulnerabilidade existencial, esta última diretamente relacionada à condição de desamparo, condição primeira e fundamental para a constituição do ser falante.

Palavras-chave: Contemporaneidade; Clínica Psicanalítica; Desamparo; Vulnerabilidade.

\begin{abstract}
Based on everyday reports, this work reflects on phenomena that present themselves in the contemporaneity with characteristics of explicit and on the scope of the psychoanalytic clinic, both with respect to the complaints and demands that are presented in diverse forms and with unusual dressing, and with respect to strategies that should be established throughout the analytical process. Concerns about these phenomena provoke questions from psychoanalysts, philosophers, anthropologists, psychiatrists, among others, regarding changes in the contemporary world and the commitment to construct a new clinic that responds to the new symptomatic modes from a new ethics. Considering the dialogue between psychoanalysis and several other fields of knowledge, this theoretical essay establishes a relationship between contemporaneity, psychoanalytic clinic and the notion of human, highlighting the two main meanings of the concept of vulnerability, namely social vulnerability and existential vulnerability, the latter directly related to the condition of helplessness, a first and fundamental condition for the constitution of the speaking being.
\end{abstract}

Keywords: Contemporaneity; Psychoanalytic Clinic; Helplessness; Vulnerability. 


\section{Introdução}

Ao contrário do que se acreditou por muito tempo, na contramão de um saber estático e preestabelecido que modela o sujeito e a sua realidade, sustentado no dualismo entre normal e patológico, consideramos que a clínica é viva, pulsante, se constrói e se reconstrói ao longo do tempo, numa tessitura onde cada nó reabre possibilidades. A realidade é ingrediente para que os conceitos e o proceder do analista se refaçam a cada passo. Passo a passo. Ao mesmo tempo, revertam e inspirem novos modos de estar no mundo.

Vamos trazer retalhos, reflexões, pontos que nos inquietam. Não se trata de refletir aposteriori, mas de viver na cena, aqui e agora. Somos leitores do nosso próprio tempo e, por isso, também autores. As transformações se dão ao mesmo tempo em que refletimos. E, ao refletirmos, já estamos no passado. Que tempo é esse?

Esta é a nossa primeira inquietação - o tempo. Desde Einstein, o tempo/espaço não é absoluto, mas precisa ser lido no caso a caso. A relatividade não é sinônimo de relativismo, trivial e inconsistente, mas se refere a cada objeto e aponta para a leitura do particular. Estamos na era da velocidade e, ao mesmo tempo em que queremos a satisfação imediata, vislumbramos o futuro travestido de ideal. Ideal estimulado pela mídia, mas também conquistado ilusoriamente pela possibilidade de acesso virtual.

Tomemos duas vertentes da arte como referência para representar esta realidade: 0 cinema, com o filme argentino Relatos Selvagens, dirigido por Damián Szifron e lançado em $2014^{1}$ e a literatura, com o texto de ficção, clássico de Huxley (1932), Admirável Mundo Novo².

O filme nos faz refletir sobre a intensidade dos nossos atos, sobre a impulsividade que se realiza no co- tidiano da nossa sociedade. Algo estranho se apresenta naquela sala de projeção. Não sabemos se rimos ou choramos. Mais ainda, estamos impactados com a crueza das cenas e com a tênue separação entre o cômico e o trágico. Algo se revela e não é inócuo. Reflete nossas almas e, ao mesmo tempo, é absolutamente distante. Está fora, sem sentido. Do que se trata? Relatos selvagens de uma dita civilização. Por outro lado, na literatura, Huxley (1980), com seu Admirável Mundo Novo, não tão novo assim, preconiza o que será das consequências do capitalismo e ficciona sobre o que, no século seguinte, se concretiza. Seria tão óbvio? Ou Huxley teve o que cada vez mais se impõe, isto que poderíamos chamar premonição? Afinal, na contemporaneidade, premonição pode ser considerada uma espécie de percepção antecipada, algo que, para além dos órgãos de sentidos, se apresenta de forma cada vez mais frequente. $O$ fato é que Admirável Mundo Novo chegou e somos dele os seus personagens.

Como dizem que a arte imita (ou será que inventa?) a vida, passemos adiante. Segundo Darwin (2003), o ser humano é descendente do macaco. A máquina do desenvolvimento evolucionista foi ligada e é preciso se perguntar para onde vamos a partir de agora. Ou será que o homem é o ser mais evoluído dos planetas e, isso, para sempre?

Também a Darwin é atribuída a afirmação de que não são os mais fortes ou os mais inteligentes que sobreviverão, mas aqueles que melhor se adaptarem. Entendamos adaptar não como se acomodar a formas impostas, pois, antigas respostas não se aplicam a novas provocações, mas como a possibilidade de incluir novos sentidos e, consequentemente, novos questionamentos.

\section{Depois da arte, fatos...}

\section{Maio de 2014 - Morre mulher linchada no Guarujá (SP) por suspeita de realizar magia negra}

\footnotetext{
'Relatos Salvajes é um filme de 2014, dirigido por Damián Szifrón, que trata de um fenômeno contemporâneo importante. Diante do que se impõe na realidade, seja em situaçães de extrema pressão ou em casos de frustração, muitas vezes mínima, o sujeito contemporâneo responde impulsivamente. Trata-se de um curto circuito entre o pensar e o agir, sem ajuizamento, sem cálculo. As personagens se lançam no limite tênue entre o normal e o patológico, entre a civilização e a barbárie. Além disso, o filme provoca uma sensação de estranhamento no expectador que, como no texto O Estranho de Freud ([1919] 1996a), mesmo ao se chocar com as cenas de agressividade explícita, tem acesso aos seus próprios impulsos, desejos e medos.

${ }^{2}$ Admirável Mundo Novo trata de uma sociedade de castas biologicamente definidas, organizada segundo princípios científicos, onde as pessoas são, desde o nascimento, programadas e adestradas em laboratório. Nesta sociedade, onde qualquer manifestação artística é considerada estímulo ao conformismo, o que se valoriza são as ideias de Henry Ford que visam o avanço da técnica, a linha de montagem, a produção em série, a uniformidade. $O$ romance de Aldous Huxley assume uma função quase premonitória, apontando para uma sociedade capitalista, industrial e tecnológica, em que a racionalidade se tornou a nova religião, a ciência é o novo ídolo, um mundo no qual a experiência do sujeito não parece mais fazer nenhum sentido. Assim, o clássico de Huxley, mais do que um mero exercício de futurismo ou de ficção científica, é uma reflexão atual sobre a nossa sociedade (Huxley, 1980).
} 
De acordo com o site de notícias da Uol (http:// noticias.uol.com.br/ultimas-noticias/agencia-estado/2014/05/05/morre-mulher-linchada-pela-populacao-no-guaruja.htm), morreu na manhã desta segunda-feira (5) de maio, em Guarujá, no litoral paulista, a mulher de 31 anos que foi espancada na noite de sábado (3) por populares, na comunidade de Morrinhos 1, sob a acusação de ser a sequestradora de crianças para rituais de magia negra. $O$ ex-marido, um porteiro de 40 anos, já foi ouvido pela polícia e inocentou a mulher. Ele disse que ela era portadora de transtorno bipolar e que fazia tratamento psiquiátrico, mas que de modo algum é a pessoa apontada como sequestradora. $O$ porteiro acredita que a mulher foi confundida com o retrato falado publicado em uma rede social que alertou os pais da comunidade sobre a presença da sequestradora em Morrinhos.

\section{Dezembro de 2014}

O site de notícias da BBC de Portugal (www.bbc. $\mathrm{com} /$ portuguese/noticias/2014/12/141202_ hawking_inteligencia_pai) em destaque, revela que - físico britânico Stephen Hawking afirmou nesta terça-feira $(02 / 12)$, em entrevista à $B B C$, que a inteligência artificial é uma ameaça à raça humana. A declaração foi feita durante uma sessão de perguntas e respostas sobre seu novo sistema de fala que ficou 10 vezes mais veloz. Ele reconhece que as máquinas tenham grande utilidade no dia a dia, mas teme o desenvolvimento desses aparelhos e o esforço de cientistas em torná-los pensantes, de forma que sejam equivalentes ou mesmo superiores aos humanos. "Os humanos, limitados pela evolução biológica lenta, não conseguiriam competir e seriam desbancados [pelas máquinas inteligentes]."

Notícias como estas provocam reflexões a respeito do mundo em que vivemos e, pelo menos por enquanto, ainda conseguem, felizmente, nos impactar. E se passar a ser apenas coisa de humanos? Vivemos no limite da atuação, onde o recalque freudiano parece não dar mais conta. $O$ aumento da violência sobre forma de barbárie rouba a cena no teatro da vida. Os relatos acima apontam para uma sociedade que, por um lado, mata e se autoriza a fazer justiça com as próprias mãos e, por outro, teme ser destruída por aquilo que cria. Mais uma vez, como no mito de Golem ${ }^{3}$, criador e criatura se confrontam (Seligmann-Silva, 2007).

\section{O Laboratório - Para além da arte e dos fatos, artefatos... Proposta de formulação de uma pragmática.}

Diante de fenômenos como estes surge a necessidade de reflexões e aprofundamento sobre as transformações da clínica psicanalítica no século $X X I$, tanto no que diz respeito às queixas e demandas que se apresentam de formas diversificadas e com roupagens inusitadas, quanto às estratégias de abordagem que devem ser estabelecidas ao longo do processo analítico. As inquietações diante destes fenômenos provocam, não só psicanalistas, mas, filósofos, antropólogos, psiquiatras, entre outros, a pensar/produzir sobre a questão, de forma mais sistemática. O Laboratório de Psicanálise (Apêndice A) é consequência do questionamento em relação a essas mudanças e propostas do mundo contemporâneo e aposta na construção de uma nova clínica que responda aos novos sintomas a partir de uma nova ética. Deste modo, além do Laboratório - lugar de labor, de fazer, de criar, de inventar - surge a necessidade de incluir um Observatório que lança luz sobre a nossa realidade e aponta para possibilidades diferentes de se posicionar frente a ela. $O$ Observatório não é necessariamente um lugar concreto, mas uma posição crítica que busca constantemente um deslocamento em relação ao que está posto prévia e automaticamente. Trata-se de produzir novos fazeres, a partir das leituras frente ao que se apresenta como desafio no século XXI.

\section{Voltemos ao nosso título: A Clínica Psicanalítica do século XXI - De que humano se trata?}

Partimos de três significantes fundamentais: Clínica Psicanalítica, Contemporaneidade, Humanos. 


\section{Clínica Psicanalítica}

Só podemos compreendê-la como práxis, articulação entre teoria e prática que visa novas leituras e a construção de novos fazeres frente à realidade. Na contemporaneidade, acreditamos ser necessário sair da análise de conflitos para a leitura de posição do sujeito frente ao seu dito (Villalba, 2008).

Existe na atualidade uma busca de resposta imediata sustentada no ideal de cura e centrada na eliminação do sintoma. Concordamos que este efeito-sintoma, isso que aparece inicialmente como queixa, deve ser, sim, inicialmente acolhido, pois esconde e revela algo da verdade do sujeito. Entretanto, ao invés de eliminá-lo, deve-se desmontá-lo, passo a passo, apontando para as razões que o sustentam e indicando a necessidade do resgate do questionamento sobre as suas causas.

O fenômeno é da ordem do universal e pode ser lido a partir de vários olhares e perspectivas. Acreditamos que a Psicanálise, em articulação com outros campos disciplinares, colabora no sentido da produção de novos modos de leitura do fenômeno. Assim, se por um lado, cada saber instituído conserva rigorosamente os seus pressupostos, na relação com outros saberes inaugura um novo campo, fruto de diferentes formas de amarração, que abre diferentes possibilidades de compreensão sobre os modos de adoecimento apresentados na contemporaneidade. Desta forma, saímos da universalidade do fenômeno, ratificando a força da clínica do singular.

que se apresenta no mundo e, consequentemente, na clínica, são outros modos de organização, outros modos de amarração, novas respostas sintomáticas que questionam saberes preestabelecidos, apontando para a necessidade de revisão de formas standards e da construção de novos modos de abordagem. A concepção de um método único, absoluto e universal se desloca. Vivemos na era de um pluralismo científico metodológico que, sem cair na trivialidade e na inconsistência, com rigor e formalização, clama por aberturas e questionamentos.

\section{Contemporaneidade - Século XXI}

Segundo Agamben (2012), contemporâneo é aquele que lança luz na obscuridade do seu tempo. Não se trata de um tempo cronológico apenas, mas da possibilidade de transformá-lo. Neste sentido, somos contemporâneos.

Este recorte aponta para a necessidade de nos situarmos no tempo/espaço, refletindo sobre as mudanças na racionalidade a partir de avanços produzidos pela ciência e vice versa. Assim, se, por um lado, a ciência produz um novo homem, novos modos de raciocínio, estes, por sua vez, produzem efeito no mundo, novas tecnologias, novos expedientes para lidar com o inusitado, novos modos de gozo.

Na passagem do geocentrismo para o heliocentrismo, com a descoberta de que a terra não é o centro do universo, por exemplo, alguns autores acreditam que o homem perde as referências, tendo que transformar as estruturas de seu pensamento e se reposicionar diante do objeto do saber. Essa perda de referência provocaria uma desestabilização psíquica que faria o homem se movimentar em busca de outro eixo a partir do qual pudesse agir e pensar (Koyré, 1973).

Da mesma forma, a virada do século XX é marcada pela emergência de novas teorias científicas que modificam os saberes constituídos e colocam em xeque verdades consideradas absolutas. As profundas transformações ocorridas no campo da ciência apontam para a necessidade de revisão de conceitos que até então estruturavam o mundo: a noção de realidade, a concepção de espaço/tempo, a hegemonia do espaço euclidiano (Rêgo, 2014). E, finalmente, no século XXI, a biologia descobre uma quase imortalidade e desliga a reprodução do sexual. Num casamento quase que perfeito com a física, começa a mudar os destinos da humanidade ${ }^{4}$. Estas descobertas e invenções apontam para a necessidade da revisão constante de paradigmas que produzem efeitos na racionalidade.

\footnotetext{
${ }^{4}$ Referência à teoria de Quase Verdade do matemático e lógico Newton da Costa (1999) que estende o conceito escolástico de verdade à noção de verdade parcial aplicada inclusive aos fundamentos da ciência. A teoria de Quase Verdade nos aproxima do impossivel e da incompletude, concepções fundamentais na sustentação da teoria psicanalítica, assim como nos faz refletir sobre o conceito bachelardiano de Conhecimento Aproximado (Bachelard, [1927] 2004). Newton da Costa é o criador da Lógica Paraconsistente (Da Costa, 1999) que derroga o princípio da não-contradição, característico da Lógica Clássica.
} 
O ideal de nossos dias passa pela busca de uma supervalorização estética e pela tendência ao desaparecimento de noções éticas de alteridade e reconhecimento da diferença. Pelos avanços da genética, vivemos a ilusão da imortalidade. Pela internet, rompemos as barreiras do tempo/espaço e criamos um mundo paralelo, onde a fantasia perde a dimensão do inatingível. $O$ homem contemporâneo não suporta a proximidade excessiva, o que parece justificar a adesão crescente às relações virtuais onde self e corpo são desvinculados e os laços sociais, enfraquecidos na materialidade, ganham formas mais toleráveis. Além disso, numa sociedade que estimula excessivamente a competição, o mundo virtual é palco perfeito para malabarismos sexuais e piruetas existenciais (Rêgo, 2004).

Neste mundo globalizado, sustentado pelo discurso do capitalismo, o que impera é a lógica da satisfação imediata, a anulação das diferenças e a sua contrapartida, a segregação, a perda de referenciais éticos e sociais. A sociedade do espetáculo 5 é caracterizada pela hegemonia da aparência e do autocentramento que, paradoxalmente, supervaloriza o ter em detrimento do ser. Assim, se por um lado, o homem contemporâneo busca a perfeição física e se orgulha dos feitos individuais, respaldado na competitividade exacerbada, por outro, o que Ihe dá sustentação é a quantidade de objetos que consegue obter, já que se depara com a falta de ideais ou referenciais aos quais possa se dirigir (Birman, 2003).

Esta falência de referenciais onde está em jogo a destituição da autoridade, aponta para uma certa fragilização do simbólico que capenga diante do bombardeio de estímulos e convocações que vivenciamos na atualidade. Assim, defrontamo-nos com um curto circuito sem intermediação simbólica, uma quase impossibilidade de representação e a consequente necessidade de extravasar, atuando, sem filtro, no corpo e/ou no mundo.

O discurso mercadológico - de consumo irrestrito - e - avanço científico tecnológico, que vende férias no espaço sideral, nos dizem a todo o momento que é possível ter acesso a tudo - o que foge da máxima freudiana que impera desde o século XIX e que sustenta o mundo ocidental, ou seja, aquilo que Freud estruturou como $\circ$ inconsciente, apontando que há algo que falta desde sempre.

Além disso, estamos na era da velocidade e os saltos gigantescos dados pela ciência apontam para a necessidade do psicanalista operar de forma cada vez mais precisa e veloz, fazendo de uma sessão analítica um acelerador de verdades que provoque efeitos que nem sempre são observados no mundo exterior (Laurent, 2000). Negligenciar a discussão com a ciência atual mantém a Psicanálise à margem do pensamento contemporâneo sobre o mundo marginalização que redundará no impedimento de que ela continue a ser filha da época em que vive e, por conseguinte, em sua fossilização (Faveret \& Coutinho 1997).

\section{Humanos}

Cabe aqui a distinção entre ser humano e ser falante. A psicanálise não tem como objeto o ser humano na perspectiva psicológica, social e biológica, mas lida com um conjunto de operações lógicas que constituem um ser dividido. Trata-se do homem como ser falante, mergulhado em uma cultura antes mesmo de seu nascimento, que sofre determinações desse sistema simbólico que é a linguagem, ingressando, de formas mais diversas, nessa ordem simbólica a partir da relação com o Outro.

O que define, então, o humano para a psicanálise? O humano é um ser de linguagem. Não um ser de fala, mas de linguagem. As palavras não têm correspondência exata com o objeto da realidade, elas deslizam, se remetendo sempre a um outro lugar, representando algo. O que define o humano é a racionalidade, a possibilidade de simbolizar e de inventar. Mas, o que acontece se perdemos a possibilidade de simbolizar, ou, dito de outra forma, quando o objeto passa a ter um caráter concreto, real, de objeto em si, perdendo a dimensão de coisa a ser nomeada?

${ }^{5}$ Referência ao trabalho de Guy Debord (Paris,1931-1994), publicado pela primeira vez em 1967, sobre alguns conceitos desenvolvidos por Marx e suas consequências no mundo contemporâneo. Debord faz uma crítica à sociedade de consumo capitalista, intitulando-a de "Sociedade do espetáculo", refletindo sobre as características das relações sociais desta sociedade e sobre a função da imagem que ganha vida própria na contemporaneidade e o poder de colocar o sujeito no lugar de espectador (Debord, 2003). 
Adorno (2003) se refere à coisificação das relações humanas, o que provoca, segundo ele, a perda da dimensão humana no sentido clássico. Trata-se de uma consciência coisificada, onde as pessoas, além de se equipararem às coisas, transformam as pessoas e as suas relações em coisas. Neste sentido, lembra Paul Valéry que afirma, já antes da segunda guerra mundial, que a inumanidade teria um grande futuro.

Neste mesmo texto, Adorno (2003), faz referência à técnica, lembrando que a mesma não tem vida própria, é um prolongamento do homem e, portanto, fruto da relação que o homem estabelece com ela. A relação do homem com a técnica aparece, muitas vezes, na atualidade, de forma irracional, patológica e exagerada, mas é fruto da função que ela assume e do modo de uso que se faz dela. "Os meios - e a tecnologia é a essência dos meios para a autopreservação da espécie humana - são fetichizados, porque as finalidades - uma existência digna do ser humano - são encobertas e arrancadas do consciente humano" (Adorno, 2003, p 130)

Já Canguilhem (2002), ainda em relação à técnica, afirma que os instrumentos da ciência contemporânea não são mais objetos auxiliares, como se considerava até então, mas os novos órgãos da inteligência, substitutos dos órgãos de sentido.

A relação do homem contemporâneo com a técnica é fundamental para pensarmos na sua relação com - mundo e para introduzirmos a noção de falta - a importância da falta e, consequentemente, o conceito de vulnerabilidade existencial ou vulnerabilidade constitutiva, que a Psicanálise chama de desamparo, e que é o tema deste encontro.

Neste ponto, precisamos distinguir a vulnerabilidade existencial (ou constitutiva) da vulnerabilidade social, esta última, na medida do possível, poderá ser questionada e reparada, enquanto a vulnerabilidade existencial é fundamental para nos tornarmos humanos.

A palavra vulnerável origina-se do verbo latim vulnerare, que significa ferir, penetrar. $O$ conceito, mais usado corriqueiramente como vulnerabilidade social, é multidimensional e se refere à condição de indivíduos ou grupos em situação de fragilidade, fragilidade esta que os tornam expostos a riscos e a níveis significativos de desagregação social. Relaciona-se ao resultado de qualquer processo acentuado de exclusão, discriminação ou enfraquecimento de indivíduos ou grupos, provocado por fatores tais como pobreza, crises econômicas, nível educacional deficiente, localização geográfica precária e baixos níveis de capital social, humano ou cultural. Pode significar ainda "susceptibilidade à deterioração de funcionamento diante de estresse" (Janczura, 2012, p.302), o que remete à relação entre os indivíduos e às suas suscetibilidades ou predisposições a respostas ou consequências negativas. Essa perspectiva reconhece as complexas interações entre as vulnerabilidades, as forças individuais, $\circ$ ambiente e a presença ou não de suporte social.

Já em segurança de computadores, vulnerabilidade é uma fraqueza que permite que um atacante reduza a garantia de informações de um sistema, gerando deficiências na segurança geral do computador ou da rede. Vulnerabilidade, neste caso, é a interseção de três elementos: suscetibilidade ou falha do sistema, acesso do atacante à falha e capacidade do atacante de explorar a falha. Falhas que, na medida do possível, poderão ser medidas, controladas, reparadas. Se tomarmos o exemplo do computador para ilustrarmos a vulnerabilidade humana, estamos diante de um atacante potencial, mas também de um dito sistema falho que possibilita ou não que o atacante $o$ invada.

Quanto à vulnerabilidade existencial, ela está diretamente ligada à condição de desamparo, condição primeira e fundamental do ser falante. $O$ filhote humano nasce fisiologicamente imaturo e não sobrevive inicialmente sem a presença do Outro. Entretanto, essa relação direta e absoluta com o Outro deve ser de alguma forma ultrapassada para que ele possa alcançar uma certa autonomia e decidir sobre a sua existência. A superação desta condição de desamparo instaura no ser falante a possibilidade de se reconhecer como faltante e de lidar com questões existenciais que aparecem ao longo do tempo e que são impossíveis de preencher de forma absoluta. Esta superação, entretanto, não é definitiva, mas processo de idas e vindas, onde o ser falante terá que se defrontar para sempre com isso que é marca indelével de sua condição. 


\section{Considerações finais}

Na contemporaneidade, o progresso da ciência sobretudo com o avanço tecnológico e farmacológi$\mathrm{co}$, as pesquisas genéticas, as descobertas no campo da reprodução assistida, entre outros - e o discurso do mercado - com seu imperativo de consumo irrestrito e de satisfação imediata - dão ao homem contemporâneo o engano da completude. $O$ Mito do Andrógino, discursado por Aristófanes, personagem de Platão em $O$ Banquete (Apêndice $B$ ), que relata a eterna busca do homem pela outra metade que outrora lhe pertencia, parece se concretizar, mesmo que de forma enganosa, nos tempos atuais.

Se, por um lado, o ser humano, por ter acesso a tantos novos objetos, se pensa cada vez mais potente, quase imortal, paradoxalmente, se representa frágil, incapaz de lidar com qualquer frustração, tendo que recorrer irremediavelmente a expedientes externos que funcionam como bengalas imaginárias. $O$ humano se torna, de certo modo, aprisionado neste jogo binário, marca do pensamento clássico, entre a onipotência e a impotência.

Sair desta dualidade é considerar a existência de uma falta, impossível de ser preenchida por qualquer tipo de objeto, o que convida o humano a inventar um modo particular de lidar com aquilo que escapa a uma resolução definitiva e absoluta. Esta falta, constitutiva do ser falante, também considerada como vulnerabilidade existencial, possibilita a instalação de novas saídas que fujam da armadilha da vitimização e/ou do seu extremo oposto, a atuação impulsiva e sem limites.

A possibilidade de se reconhecer faltante e de buscar alternativas para sair do engano da completude, inventar diante do impossível, eis o nosso desafio. Dessa forma, dirigimos na contramão de alguns discursos dominantes caracterizados pelo imperativo da resposta imediata e do consumo exacerbado que tentam desesperadamente apagar qualquer vestígio de subjetividade, e incluímos razões no reinado absoluto do consumo. Aliás, vale ressaltar que consumir significa, nada mais nada menos, que apagar, desaparecer, gastar, destruir, debilitar, aborre- cer. A Psicanálise, ao contrário, inscreve, revela, dá nome, lança um olhar sobre o que se apresenta no mundo e na atualidade, mais do que nunca, busca desmascarar o véu que tenta cobrir de formas mais diversas o que simplesmente é da condição humana.

\section{Conflitos de interesses}

Nenhum conflito financeiro, legal ou político envolvendo terceiros (governo, empresas e fundações privadas, etc.) foi declarado para nenhum aspecto do trabalho submetido (incluindo, mas não se limitando a subvenções e financiamentos, conselho consultivo, desenho de estudo, preparação de manuscrito, análise estatística, etc.).

\section{Referências}

Adorno, W. T. (2003). "Educação após Auschwitz". In Educação e Emancipação. (3a ed., pp. 119-138). São Paulo: Paz e Terra.

Agamben, G. (2012). O que é o contemporâneo? e outros ensaios. Santa Catarina: Argos.

Almodóvar, P., \& Kuschevatzky, A. (produtores) \& Szifron, D. (Diretor). (2014). Relatos Selvajens [DVD]. Argentina, Espanha: Estúdio: Telefe; El Deseo; Kramer \& Sigman Films; Coner Contenidos; Instituto Nacional de Cine y Artes Audiovisuales. Recuperado de http://123hulu. com/watch/RGbyJbxY-relatos-salvajes.html

Birman, J. (2003). Mal-estar na atualidade: a psicanálise e as novas formas de subjetivação. (4a ed.). Rio de Janeiro: Civilização Brasileira.

Canguilhem, G. (2002). Gaston Bachelard et les philosophes. In G. Canguilhem. Études d'histoire et de philosophie des sciences (7a ed., pp. 187 - 195.). Paris: J. Vrin.

Darwin, C. (2003) A Origem das Espécies e a Seleção Natural. São Paulo: Hemus.

Faveret, B. M. S., \& Coutinho, R. A. (1997). Psicanálise e Biologia: o adoecer psíquico repensado a partir do paradigma informal. (Tese de doutorado). Pontifícia Universidade Católica do Rio de Janeiro, Rio de Janeiro, RJ, Brasil. 
Freud, S. (1996a). Estranho (1919) (pp.235-267). In: Uma neurose Infantil e outros trabalhos (1917- 1918) (Vol. 17). Edição Standart Brasileira das Obras Psicológicas Completas de Sigmund Freud. Rio de Janeiro: Imago.

Freud, S. (1996b). O Mal-estar na Civilização (1930 [1929]) (pp. 73-151) ln: O futuro de uma ilusão: O mal-estar na Civilização e outros trabalhos (1930). (Vol. 21); Edição Standart Brasileira das Obras Psicológicas Completas de Sigmund Freud. Rio de Janeiro: Imago. Favor verificar essa referência

Huxley, A. (1980). Admirável Mundo Novo. São Paulo: Abril Cultural.

Janczura, R. (2012) Risco ou vulnerabilidade social? Revista Textos \& Contextos, 11 (2), 301-308. Recuperado de http://revistaseletronicas.pucrs.br/ojs/index.php/ fass/article/view/12173/8639

Koyré, A. (1973) Du monde clos à l'univers infini. Paris: Gallimard.

Lacan, J. (2005) O seminário, livro 10: A angústia. Rio de Janeiro: Jorge Zahar.

Laurent, E. (2000, novembro). As paixões do ser. VII Jornada da Escola Brasileira de Psicanálise-Bahia. III Jornada do Instituto de Psicanálise da Bahia. Salvador, BA, Brasil.

Rêgo, M. (2004). Eu sou seu prisioneiro. In Almeida, A. R., Nery Filho, A., MacRae, E., Tavares, L. A. (Coord.), \& Ferreira, O. S., Drogas: tempos, lugares e olhares sobre seu consumo (pp. 153) Salvador: Edufba; CETAD/ UFBA.

Rêgo, M. (2014). Filosofia do Não: movimentos de uma nova epistemologia. (Dissertação de mestrado). Programa de Pós-graduação em Filosofia, Faculdade de Filosofia e Ciências Humanas, Universidade Federal da Bahia, Salvador, BA, Brasil.

Seligmann-Silva, M. (2007). O Golem: Entre a técnica e a magia, aquém da bioética. Remate de Males, 27(2), 183-195. Recuperado de https://periodicos. sbu.unicamp.br/ojs/index.php/remate/article/ view/8636003/3712. Doi: 10.20396/remate. v27i2.8636003

Villalba, I. (2008). Outra Razão: Ser Falante. Revista de Psicanálise Textura, 7(7). Recuperado de http://www. revistatextura.com/revista7/mat8.htm

Soares, E. (2012). Mito do Andrógino (Banquete de Platão). Recuperado de https://www.recantodasletras.com.br/ mensagensdeamor/3544395 